\title{
Treated Plasmodium berghei infected pregnant mice by Andrographis paniculata tablet (AS201-01) decreasing the TLR-4 expression and apoptosis index of placental tissue
}

\author{
Budi Prasetyo ${ }^{1}$, Diantri Nari Ratih ${ }^{1}$, Yustinasari ${ }^{1}$, Hilkatul Ilmi², Lidya Tumewu², Aty Widyawaruyanti ${ }^{2,3 *}$ \\ ${ }^{1}$ Department of Obstetrics and Gynecology, Faculty of Medicine, Universitas Airlangga, Surabaya 60131, Indonesia. \\ ${ }^{2}$ Institute of Tropical Disease, Universitas Airlangga, Surabaya 60115, Indonesia. \\ ${ }^{3}$ Department of Pharmacognosy and Phytochemistry, Faculty of Pharmacy, Universitas Airlangga, Surabaya 60286, Indonesia.
}

\begin{tabular}{l}
\hline ARTICLE INFO \\
\hline Article history: \\
Received on: 02/01/2018 \\
Accepted on: 08/03/2018 \\
Available online: 29/04/2018 \\
\hline Key words: \\
TLR-4 expression, Apoptosis \\
index, Plasmodium berghei, \\
in vivo assay, Andrographis \\
paniculata tablet (AS201-01).
\end{tabular}

\begin{abstract}
Objective: This study aimed to evaluate the effect of Andrographis paniculata tablet (AS201-01) in decreasing expression of Toll-Like Receptor-4 (TLR-4) and apoptosis index of placental tissue of Plasmodium berghei infected pregnant mice. Material and methods: A total of 24 pregnant mice were divided into 4 groups, G1 was uninfected pregnant mice group, G2 was untreated Plasmodium berghei infected pregnant mice, G3 was $P$. berghei infected pregnant mice treated with AS201-01 tablet and G4 was P. berghei infected pregnant mice treated with dihydropiperaquine-phosphate (DHP) tablets. All mice were sacrifice at day $15^{\text {th }}$ of pregnancy and the placenta was collected. The TLR-4 expression and apoptosis index were evaluated using immunohistochemistry assay. Results: The TLR-4 expression and apoptosis index on G3 was lower than G2 and showed a statistically significant difference $(\mathrm{P}=0.00)$. The TLR-4 expression and apoptosis index of placental tissue in P. berghei infected pregnant mice which treated with AS201-01 tablet were decreased compared to untreated group and DHP tablet treated group as well. Conclusion: AS201-01 tablet containing ethyl acetate fraction of $A$. paniculata could decrease TLR-4 expression and apoptosis index of placental tissue in $P$. berghei infected pregnant mice.
\end{abstract}

\section{INTRODUCTION}

Malaria is a tropical disease caused by Plasmodium infection. Pregnant women and fetus are subjects at high risk of malaria infection. Plasmodium which infected pregnant women will accumulate in placenta. Pregnancy is a unique condition as there is a changing in antibodies and immune system. These systems causing a special bond between Plasmodium proteins with receptors on the surface membrane of syncitiotrophoblast cell that lead to placental malaria (Eriksson et al., 2013).

In the patient's body, Plasmodium-infected erythrocytes will stimulate the immune response Th-1 to produce INF- $\gamma$ in high quantities and increase the number of potential receptors

${ }^{*}$ Corresponding Author

Aty Widyawaruyanti, Department of Pharmacognosy and Phytochemistry, Faculty of Pharmacy, Universitas Airlangga, Surabaya 60286, Indonesia.E-mail:aty_ww@yahoo.com such as CD36, TLR-4, and TLR-9, on the syncitiotrophoblast cell surface (Rogerson et al., 2007). In addition, infected erythrocytes will express a Plasmodium parasite antigen protein known as Glycophosphatidyl Inositol (GPI) Plasmodium. This GPI Plasmodium protein will act as ligand parasite by identification receptors such as TLR-4, which present on the surface membranes of syncitiotrophoblast cell (Kyes et al., 2001). The binding between GPI Plasmodium and TLR-4 stimulates proinflammatory cytokines through the Myeloid Differentiation Factor 88 (MyD88) and $\mathrm{NF}-\kappa \mathrm{B}$ signaling pathways and then activates pro-apoptotic proteins (Brabin et al., 2004). Plasmodium infections may also induce the formation of Reactive Oxygen Species (ROS) which also lead to increase apoptosis via intrinsic pathways (Wang et al., 2015; Mutabingwa et al., 2005; Sharma et al., 2012).

Placental malaria may cause the increase of TLR-4 expressions and apoptosis index beyond normal thus increasing fetus complications such as abortion, low birth 
weight, intrauterine fetal growth restriction, and consequently, intrauterine fetal death (Allaire et al., 2000; Houmsou et al., 2010; Steketee et al., 2001).

One of the antimalarial drugs being developed is Andrographis paniculata which traditionally used as an antimalarial drug in Indonesia. Ethyl acetate fraction of $A$. paniculata was found to have antimalarial effect as reported in the previous study (Widyawaruyanti et al., 2014). Further study is to develop ethyl acetate fraction of $A$. paniculata which was formulated in tablet dosage form called AS202-01. The tablet was reported to inhibit the growth of Plasmodium berghei in nonpregnant mice (Widyawaruyanti et al., 2017). Our recent study resulted in another formulation of ethyl acetate fraction of A. paniculata as a tablet dosage form (called AS201-01 tablet) as well. The tablet was a potential alternative to an antimalarial drug. The effect of the tablet on $P$. berghei infected pregnant mice was unknown, in particular, the effect on TLR-4 expression and apoptosis index. Possibly along with its antimalarial activity, the tablet may also decrease TLR-4 expression and apoptosis index in $P$. berghei infected pregnant mice.

It is hoped, $P$. berghei infected pregnant mice which were treated with an AS201-01 tablet would decrease TLR-4 expression and apoptosis index so that could prevent placental malaria complication and worsening of the fetus. Therefore, this study is aimed to evaluate the effect of the AS201-01 tablet in decreasing of TLR-4 expression and apoptosis index of placental tissue in Plasmodium-infected pregnant mice.

\section{MATERIAL AND METHODS}

\section{Materials}

The AS201-01 tablet contains ethyl acetate fractions of $A$. paniculata, equivalent to $35 \mathrm{mg}$ of andrographolide per tablet. The tablet was produced at Faculty of Pharmacy, University Airlangga, Surabaya, Indonesia. DHP tablet contains dihydroartemisinin $40 \mathrm{mg}$ and piperaquine phosphatase/320 mg (D-ARTEPP ${ }^{\mathrm{TM}}$ ) was produced by Guilin Pharmaceutical Co., Ltd., Guangxi, China.

\section{Parasite}

P. berghei ANKA strain was obtained from Eijkman Institute for Molecular Biology, Jakarta. On the $9^{\text {th }}$ day post mating, mice were injected with $P$. berghei ANKA strain per 0.2 $\mathrm{ml}$ of blood intraperitoneally. This parasite has been maintained at the Institute of Tropical Disease, Universitas Airlangga, Surabaya, Indonesia.

\section{Animals}

This study used female and male mice Balb/c strain at 16 to 18 weeks of age which were obtained from the Animal Experimental Development Unit - Gajah Mada University (Yogyakarta, Indonesia). They were maintained at Animal Laboratory of Institute of Tropical Disease, Universitas Airlangga. Permission and approval for animal studies were obtained from Faculty of Veterinary Medicine, Universitas Airlangga, with ethical clearance No: 560-KE/2016.

\section{Experimental design}

Eighteen of pregnant mice were infected with $1 \times 10^{6}$ of $P$. berghei parasite on day $9^{\text {th }}$ of gestation (GD 9). These infected mice then divided into 3 groups which were G2, G3, and G4 (n $=6)$. Administered therapy was begun on day $11^{\text {th }}$ of gestation (GD 11). G2 was an untreated group. G3 was treated by AS20101 tablet, at a dose equal to $25 \mathrm{mg}$ andrographolide/ $\mathrm{Kg}$ body weight, twice daily for 4 days. Meanwhile, G4 was treated by Dihydroartemisinin Piperquine-Phosphate (DHP) tablet, once a day for 3 days. Additionally, G1 was uninfected pregnant mice $(\mathrm{n}=$ 6 ). All mice were then terminated on the $15^{\text {th }}$ day of gestation (GD 15 ) and placenta collected in formalin $10 \%$ for further analysis.

\section{Measuring TLR-4 expression and apoptosis index}

Placenta samples in paraffin blocks were stained with immunohistochemical KIT using monoclonal anti-rat TLR-4 (NBP 2-45710) Nuvosbio for measuring TLR-4 expressions and TACS-XL in situ apoptosis detection KIT (4828-30-DK) for measuring apoptosis index.

\section{Evaluation of TLR-4 expression and apoptosis index}

Observation and counting the number of TLR-4 expression and apoptosis index in placenta tissue under microscope H600L Nikon $(10 \times 100)$ were done in five fields of view. TLR-4 expression and apoptosis index was calculated used Immunoreactive Score (IRS) that referred to the result of multiplying the score of percentage immunoreactive cells with a score of color intensity on the cell immunoreactive with Tunnel assay staining. Placenta tissue that consists of syncytiotrophoblast cells undergoing DNA fragmentation will be labeled as brown chromogen.

\section{Statistical analysis}

Data was analyzed by statistical software SPSS version 17 . The normality data distribution was determined by Kolmogorov-Smirnov test. The significance of the mean difference between independent groups for normal distribution data was determined by using one-way analysis of variance (ANOVA). Meanwhile, for nonnormal distributed data was determined by using nonparametric Kruskal-Wallis test. Significance different of groups was analyzed by using Post Hoc Tukey's HSD test. A p-value $<0.05$ was considered significant.

\section{RESULTS AND DISCUSSION}

Studies to determine the effect of administration of AS201-01 tablets against TLR-4 expression and apoptosis index of placental tissue of plasmodium-infected pregnant mice were performed. Figure 1 showed the placenta TLR-4 expression in all groups. The highest TLR-4 expression was shown in G2 and the lowest in G1. The result of the statistical analysis showed that there was a significant difference $(\mathrm{P}=0.00)$ on TLR-4 expression between group G2 with G1, G3, and G4. Meanwhile, figure 3 showed means of apoptosis index in all groups. The highest apoptosis index was in G2 and the lowest in G1. The statistic analysis result using one way ANOVA showed a significant difference between $\mathrm{G} 2$ and $\mathrm{G} 1(\mathrm{P}=0.00)$ and also between $\mathrm{G} 2$ and $\mathrm{G} 3(\mathrm{P}=0.00)$. There was no significant difference in apoptosis index between $\mathrm{G} 1$ dan $\mathrm{G} 3(\mathrm{P}=0.15)$. 


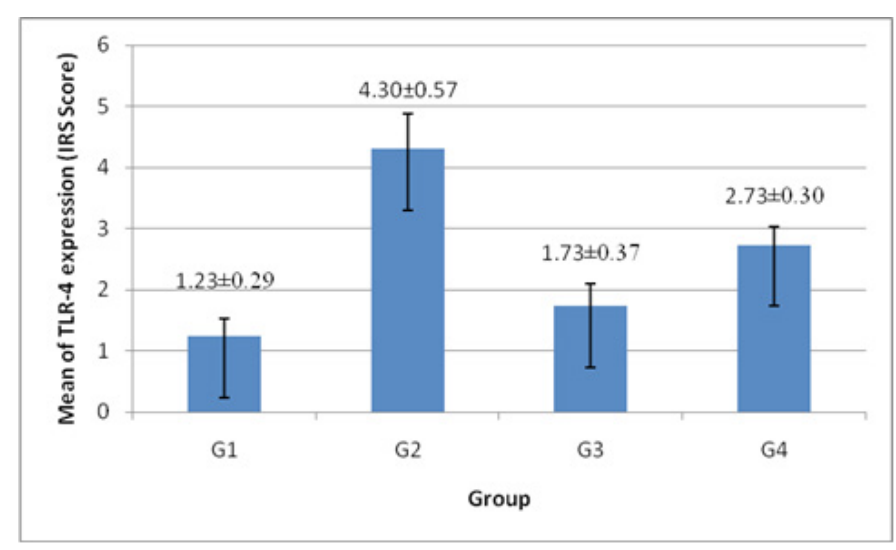

Fig. 1: Mean of placenta TLR-4 expression in all groups (G1: normal group. G2: infected untreated pregnant mice group. G3: infected pregnant mice and treated with AS201-01 tablet group, G4: infected pregnant mice and treated with DHP tablet group).

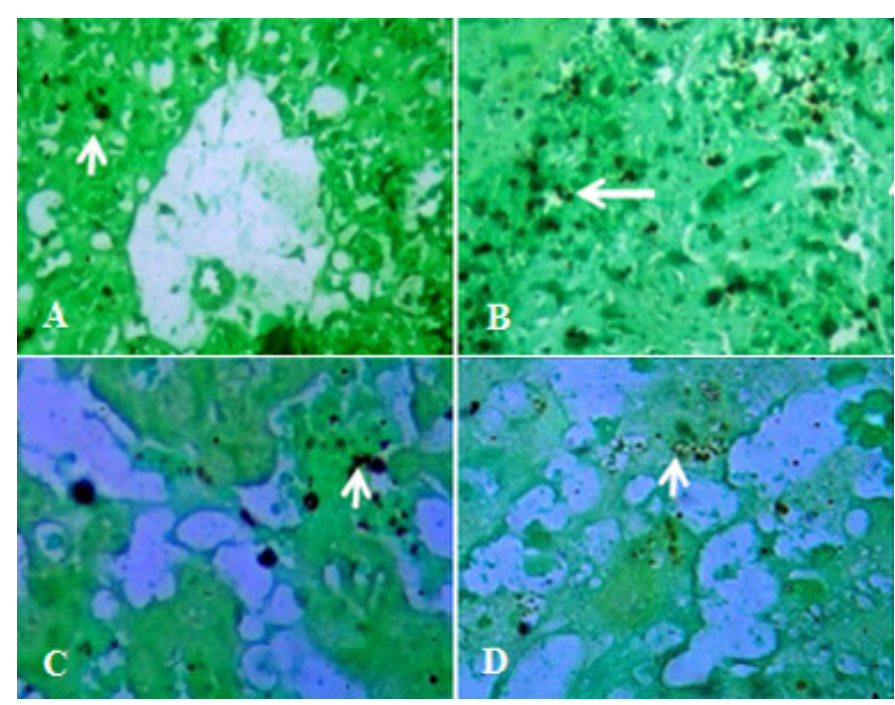

Fig. 2: TLR-4 expression in: A. normal group (G1), B. infected untreated pregnant mice group (G2), C. infected pregnant mice and treated with AS201-01 tablet group (G3), D. infected pregnant mice and treated with DHP tablet group (G4). The arrows show the TLR expression on cell membrane surface. The sample was observed under a light microscope with 100x objective magnification.

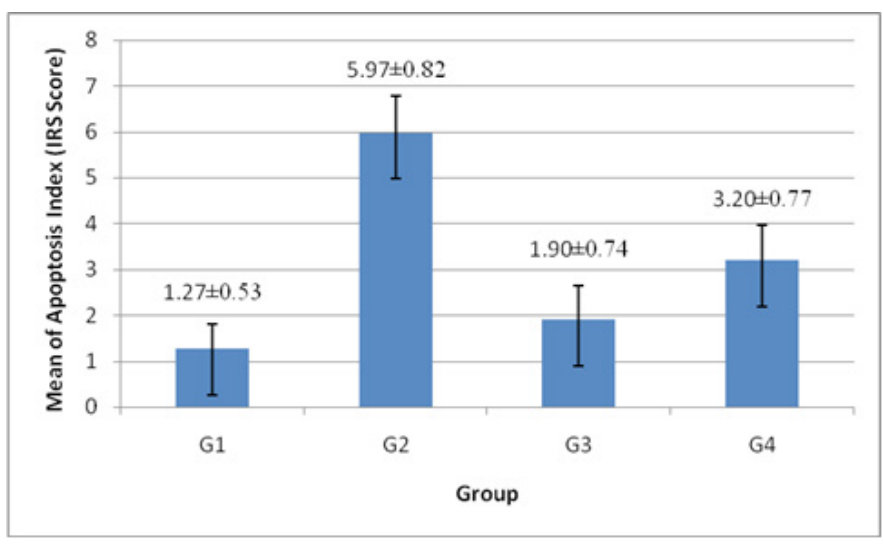

Fig. 3: Mean of placental apoptosis index in all groups (G1: normal group, G2: infected untreated pregnant mice group, G3: infected pregnant mice and treated with AS201-01 tablet group, G4: infected pregnant mice and treated with DHP tablet Group).

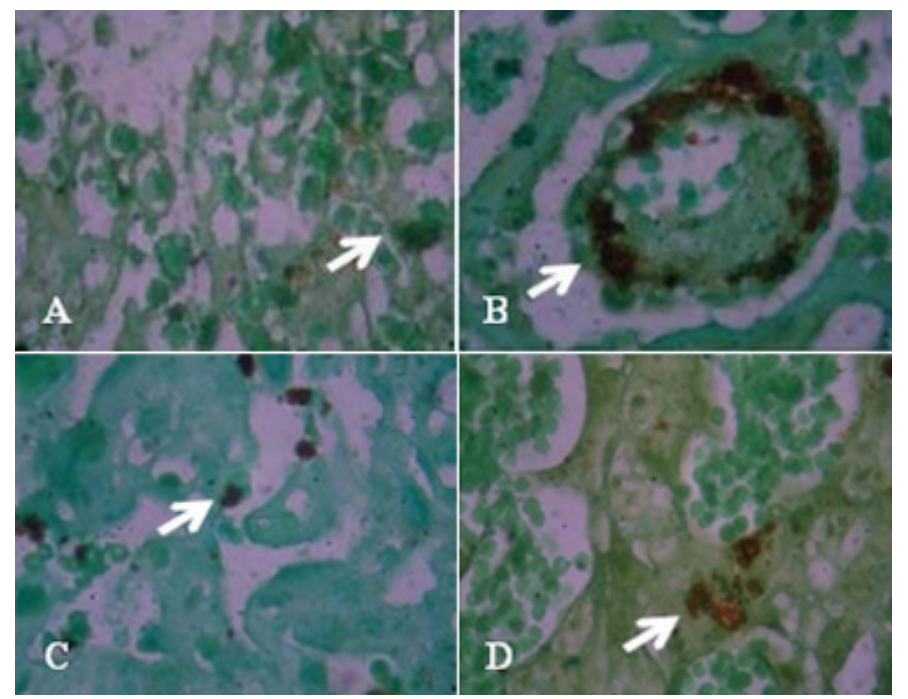

Fig. 4: Apoptosis index in: A. normal group (G1), B. infected untreated pregnant mice group (G2), C. infected pregnant mice and treated with AS201-01 tablet group (G3), D. infected pregnant mice and treated with DHP tablet group (G4). The arrows show the apoptosis on cell membrane surface. The sample was observed under a light microscope with 100x objective magnification.

The study results showed that TLR-4 expression and apoptosis index in uninfected group (G1) were low. This group was used as normal control. Meanwhile, the highest TLR-4 expression and apoptosis index was found in P. berghei infected untreated pregnant mice group (G2). This result was in accordance with previous report that found the apoptosis index of $P$. berghei infected pregnant mice was higher than in uninfected pregnant mice (Sharma et al., 2012). P. berghei infected pregnant mice which treated with A. paniculata tablet AS201-01 (G3) were showed lower TLR-4 expression and apoptosis index compared to G2. This suggests that administration of AS201-01 tablets may decrease TLR-4 expression and apoptosis index. In the placenta, apoptosis normally occurs to maintain a pregnancy. An excessive increase in apoptosis may cause a disruption of blood flow to the placenta resulting in decreased fetal weight (Rogerson et al., 2007; Allaire et al., 2000).

Table 1: Semiquantitative IRS score. The result of multiplication percentage of the immunoreactive cell (A) with color intensity score (B).

\begin{tabular}{cc}
\hline A & B \\
\hline Score 0: no positive cell & Score 0: no color reaction \\
Score 1: positive cell less than 10\% & Score 1: low color Intensity \\
Score 2: positive cell between $11-50 \%$ & Score 2: medium color Intensity \\
Score 3: positive cell between $51-80 \%$ & Score 3: high color Intensity \\
Score 4: positive cell more than $80 \%$ & \\
\hline
\end{tabular}

The ability of AS20-01 tablets in decreasing the TLR-4 expression and apoptosis index because of the $A$. paniculata effect as an immunomodulator and antioxidant, which inhibit $\mathrm{T}$ lymphocyte cells in activating TLR-4 (Lin et al., 2009; Qin et al., 2006). This TLR-4 activation inhibition leads to activation inhibition of cytokine and pro-apoptosis proteins which may decrease apoptosis index of the placenta through extrinsic pathways (Rogerson et al., 2007). It was also inhibited ROS formation thus 
decreasing apoptosis via intrinsic pathway (Rogerson et al., 2007; Brabin et al., 2004; Lin et al., 2009).

A. paniculata tablet has an antimalarial effect. The antimalarial effect is due to the andrographolide which is the major compound of this plant. The period of activity of andrographolide was found evidently on the ring stage of the parasite (Luo et al., 2013). A. paniculata extract and andrographolide effects include inhibition of the nuclear transcription factor-kappa $\mathrm{B}(\mathrm{NF}-\kappa \mathrm{B})$. Plasmodium-infected erythrocytes have shown to induce NF- $\kappa \mathrm{B}$ regulated inflammatory pathways in human cerebral endothelium. $\mathrm{NF}-\kappa \mathrm{B}$ is activated and translocated into the nucleus, where it binds to the DNA regulatory site to regulate specific gene expression, especially cell signaling for parasite growth and development. Therefore, the inhibition of transcription factor of $A$. paniculata extract against $P$. berghei ANKA might be a critical process to inhibit blood stage propagation of parasites in vivo (Luo et al., 2013; Mishra et al., 2009).

Tablets AS201-01 can be used as an alternative to treats malaria in pregnancy. Therapy with this tablet is expected to prevent the side effects of malaria in pregnancy, such as low birth weight, abortion, and fetal growth inhibited.

\section{CONCLUSION}

In conclusion, A. paniculata tablet (AS201-01) which contain ethyl acetate fraction of $A$. paniculata could decrease the TLR-4 expression and apoptosis index of placental tissue in $P$. berghei infected pregnant mice.

\section{ACKNOWLEDGMENT}

The authors acknowledge Universitas Airlangga Mandat Research Grant 2016 with contract no. 564/UN3.14/LT/2016 for funding this research.

\section{CONFLICT OF INTEREST}

There is no conflict of interest.

\section{REFERENCES}

Allaire AD, Ballenger KA, Wells SR, McMahon MJ, Lessey BA. Placental apoptosis in preeclampsia, Obstet and Gynecol. 2000; 96(2):271-6.

Brabin BJ, Romagosa C, Abdelgalil S, Menéndez C, Verhoeff FH, McGready R, et al. The sick placenta-the role of malaria. Placenta. 2004; 25(5):359-78.

Eriksson EM, Sampaio NG, Schofield L. Toll-Like Receptors and malaria - sensing and susceptibility. J Trop Dis. 2013; 2:126.
Houmsou RS, Amuta EU, Sar TT, Adie AA. Malaria infection in pregnant women attending antenatal clinics in Gboko, Benue State-Nigeria. International Journal of Academic Research. 2010; 2(1):33-36.

Kyes S, Horrocks P, Newbold C. Antigenic variation at the infected red cell surface in malaria. Annu Rev Microbiol. 2001; 55:673-707.

Lin FI, Wu SJ, Lee SC, Ng IT. Antioxidant, antioedema and analgesic activities of Andrographis paniculata extract and their active compound andrographolide. Phytother Res. 2009; 23(7):958-64.

Luo W, Liu Y, Zhang J, Luo X, Lin C, Guo J. Andrographolide inhibits the activation of NF-kappaB and MMP-9 activity in H3255 lung cancer cells. Exp Ther Med. 2013; 6(3):743-6.

Mishra K, Dash AP, Swain BK, Dey N. Antimalarial activities of Andrographis paniculata and Hedyotis corymbosa extracts and their combination with curcumin. Malar J. 2009; 8(26):1-9.

Mutabingwa TK, Bolla MC, Li JL, Domingo GJ, Li X, Fried M, et al. Maternal malaria and gravidity interact to modify infant susceptability to malaria. Plos Med. 2005; 2(12):e407.

Qin LH, Kong L, Shi GJ, Wang ZT, Ge BX. Andrographolide inhibits the production of TNF-alpha and IL-12 in lipopolysaccaridestimulated macropages: role of mitogen-activated protein kinase. Biol Pharm Bull. 2006; 29(2):220-4.

Rogerson SJ, Hviid L, Duffy PE, Leke RF, Taylor DW. Malaria in pregnancy: pathogenesis and immunity. Lancet Infect Dis. 2007; 7(2):105-17.

Sharma L, Kaur J, Shukla G. Role of oxidative stress and apoptosis in the placental pathology of Plasmodium berghei infected mice. PLoS One. 2012; 7(3):e32694.

Steketee RW, Nahlen BL, Parise NE, Menendez C. The burden of malaria in pregnancy in malaria-endemic areas. Am J Trop Med Hyg. 2001; 64(2):28-35.

Wang D, Shi J, Lv S, Xu W, Li J, Ge W, et al. Artesunate attenuates lipopolysaccharide - stimulated proinflammatory responses by suppressing TLR4, MyD88 expression, and NF- $\mathrm{KB}$ activation in microglial cells. Inflammation. 2015; 38(5):1925-32.

Widyawaruyanti A, Asrory M, Ekasari W, Setiawan D, Radjaram A, Tumewu L, et al. In vivo antimalarial activity of Andrographis Paniculata tablet. Procedia Chemistry. 2014; 13:101-104.

Widyawaruyanti A, Astrianto D, Ilmi H, Tumewu L, Widyastuti E, Dachliati L, et al. Antimalarial activity and survival time of Andrographis paniculata fraction (AS202-01) on Plasmodium berghei infected mice. Res J Pharm Biol Chem Sci. 2017; 8(1S):49-54.

How to cite this article:

Prasetyo B, Ratih DN, Yustinasari, Ilmi H, Tumewu L, Widyawaruyanti A. Treated Plasmodium berghei infected pregnant mice by Andrographis paniculata tablet (AS201$01)$ decreasing the TLR-4 expression and apoptosis index of placental tissue. J App Pharm Sci, 2018; 8(04): 105-108. 